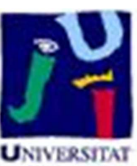

Título artículo / Títol article: SCIF-IRIS Framework: A framework to facilitate interoperability in supply chains

Autores / Autors

Verónica Pazos Corellaa, Ricardo Chalmeta Rosaleña, David Martínez Simarro

Revista:

International Journal of Computer Integrated Manufacturing

Versión / Versió:

Versió pre-print

Cita bibliográfica / Cita bibliogràfica (ISO 690):
PAZOS CORELLA, Verónica; CHALMETA ROSALEÑ, Ricardo; MARTINEZ SIMARRO, David. SCIF-IRIS framework: a framework to facilitate interoperability in supply chains. International Journal of Computer Integrated Manufacturing, 2013, vol. 26, no 1-2, p. 67-86.

url Repositori UJI: 


\title{
SCIF-IRIS Framework: A framework to facilitate interoperability in supply chains
}

\author{
Verónica Pazos Corella ${ }^{1 *}$, Ricardo Chalmeta Rosaleñ*, David Martínez Simarro** \\ *Grupo de Investigación en Integración y Re-Ingeniería de Sistemas (IRIS) \\ Universitat Jaume I. 12006 Castellón. Spain. \\ Tel:+ 34964728329 Fax: + 34964728435 \\ ** Information and Communication Technologies Department \\ AINIA Technological Center AINIA. Valencia. Spain
}

\begin{abstract}
One approach that allows improving the collaboration among all the enterprises within of a supply chain is interoperability. Interoperability allows that enterprises in the supply chain collaborate in an efficient manner while preserving their own identities and their own ways of doing business through mechanisms that act as facilitators. However, there are few real practical examples of supply chain interoperability that can be used as a reference. In this paper we present a framework that can facilitate supply chain interoperability and an example of how it can be applied to a food supply chain.
\end{abstract}

Keywords: Collaborative Network, Interoperability

\section{Introduction}

The Supply Chain (SC) can be defined as "a set of three or more entities (organizations or individuals) directly involved in the upstream and downstream flows of products, services, finances, and/or information from a source to a customer" [1]. Today, correct Supply Chain Management (SCM) has become a strategic goal in business management and is now seen as a key competitive factor [2] that is essential to be able to compete in markets that are increasingly more global, dynamic and aggressive [3]. One of the fundamental aspects involved in accomplishing correct SCM is to cut costs and improve efficiency in the collaborations that the enterprise has with its stakeholders in the supply chain [4]. Supply chain collaboration consists in coordinating and synchronizing the resources, decisions, methods, business processes, employees and technology of the different stakeholders.

The prevailing conventional wisdom in SCM literature is that the more integration is achieved, the better the performance of the supply chain will be [5]. The ideal situation, according to the Council of Supply Chain Management Professionals, is for the entire process across the supply chain to be designed, managed and coordinated as a unit. In an integrated supply chain, all the functions that make up the supply chain are viewed as a single entity rather than as separate individual functions. This homogeneity in their processes and systems implies a full (and effortless) capacity to collaborate and exchange information [6].

Yet, due to the high costs involved in integration [7], this is only cost-effective if the SC is static, in the sense that participating enterprises do not change as time goes by and market requirements remain constant. Thus, there are four possible scenarios in which integration is not feasible:

- If the market requirements often change, it would be necessary to adapt the business processes, and not only those of the enterprises that are directly involved, but also of the rest of the organizations in the chain, which will then have to integrate with one another again. The increases in competitiveness that are gained would not make the high costs of the successive integration projects worthwhile.

- If new enterprises enter the SC, they have to make a great effort, both economically and in terms of other resources, to homogenize processes, technology, knowledge, terminology, and so forth. This also represents a barrier making it more difficult for new partners to enter and can end up reducing the competitiveness of the SC.

\footnotetext{
${ }^{1}$ Verónica Pazos Corella: Departamento de Lenguajes y Sistemas Informáticos, Universitat Jaume I, Avda. Sos Banyat s/n, 12006 Castellón. Spain, vpazos@1si.uji.es, +34 964728340
} 
- If the enterprises that already belong to the SC do not want to adopt an integrated way of collaborating, that is to say, if they each want to keep their independence, their own particular way of doing things using heterogeneous systems, different tools and procedures, as well as different concepts or languages.

- If an enterprise collaborates in more than one SC, it cannot be integrated in both of them at the same time.

The concept of enterprise interoperability thus appears as a solution to such problems [8]. Many definitions of interoperability have been put forward over the years [9]. Nevertheless, in this paper enterprise interoperability is defined as the capacity enterprises and organizations have to collaborate in an efficient manner while preserving their own identities and their own ways of doing business through mechanisms that act as facilitators. In this context, preserving their identity means that each enterprise does not substantially modify its structure and processes in order to achieve compatibility with other enterprises. Interoperability is considered to have been accomplished if efficient collaboration takes place, at least, in the business, processes, and information and communication technologies (ICT) layers, and also considering aspects of semantics that complement the previous three [10].

However, in many cases, enterprises are not designed to interoperate with one another. Many of the problems arise from proprietary technological developments or ad hoc extensions, from the inexistence or excess of standards, as well as from the lack of experience and culture of the human resources. This absence of interoperability therefore has to be focused on from the organizational and technological areas. Interoperability means that people, processes and different ICTs from different enterprises are capable of interacting in a simple way.

In recent years different international initiatives have been carried out with the aim of improving the capacity for interoperability of enterprises. These projects have resulted in a remarkable amount of progress being made in the three fundamental domains of interoperability: Enterprise Modeling (EM), which deals with the representation of the inter-networked organization and considers how to ensure interoperability between different models; Architecture and Platform (A\&P), which considers the technology needed to implement interoperable applications; and Ontologies (ONTO), which ensures that the semantics used can be understood by the two systems [6].

Yet, technological progress alone is not enough. For enterprises to be competitive and their growth sustainable, the progress made in knowledge about interoperability must be transferred to applications for use in the real economy. In this respect, two of the main challenges that have to be overcome today in order to improve the interoperability of enterprises are:

(1) No frameworks with a holistic view have been designed to guide the process of improving interoperability. Such frameworks must incorporate the different improvements proposed within the different domains of interoperability; they must consider different views of the enterprise other than just technology, such as business, processes or human resources; and they must take into account financial, social and environmental aspects, and in general the feasibility of a project of this kind, which shows enterprises that they are cost effective.

(2) There are few real practical examples that can be used as a reference and act as drivers, especially in small and medium-sized enterprises.

Hence, there are a number of problems related with enterprise interoperability that remain unsolved and there is still room for a great deal of improvement in both its theoretical aspects and its practical application. To solve the above problems, this paper describes a holistic framework for supply chain interoperability that is structured in six dimensions. This research started as an exploratory work and used a case study of the food supply chain sector to show that the conceptual model was feasible. The framework is not only useful for dynamic supply chains. They can be used by any type of collaborative enterprise networks where participants changes such as virtual organizations and virtual enterprises, defining them as "production system with mainly independent enterprises as single elements, which can be dynamically insourced or outsourced depending on the market demands" [11].

To solve this problem, this paper describes a framework for supply chain interoperability that is structured in six dimensions. In order to validate and evaluate the applicability and benefits of this proposal, a case example of applying the framework to the food supply chain sector is outlined. 
This paper is organized as follows: section 2 presents a review of the literature related with the subject dealt with in the paper. Section 3 presents the framework that was developed to facilitate interoperability and thus enhance collaboration in supply chains. Section 4 outlines how it was applied in a real enterprise. Section 5 discusses practical aspects of this application and finally, in section 6, conclusions and future work are shown.

\section{Literature Review}

Bearing in mind the importance of interoperability, research groups and practitioners have made several efforts to solve interoperability problems and enhance collaborations among enterprises. These efforts have followed the lines of Enterprise Modeling (EM), Architecture and Platforms (A\&P) and Ontologies (ONTO) [6]. Frameworks have also been proposed, taking the full advantage of the advances in this field. These frameworks attempt to help during the interoperability improvement project in a supply chain. Although these frameworks have many good points, they do not completely solve all the problems found in these kinds of projects. Here are some of the most well-known frameworks [12].

The Athena Interoperability Framework (AIF) [13]. It defines a set of meta-models and languages that can be supported by tools and methods to construct interoperability models.

The Global Supply Chain Forum (GSCF). It defines a framework to improve supply chain collaborations. This framework is focused on the supply chain business process. The following eight supply chain management processes are included in the GSCF framework: Customer Relationship Management, Customer Service Management, Demand Management, Order Fulfillment, Manufacturing Flow Management, Supplier Relationship Management, Product Development and Commercialization, and Returns Management. Customer relationship management and supplier relationship management form the critical links in the supply chain and the other six processes are coordinated through them. Each of the eight processes is cross-functional and cross-firm [12].

The Supply-Chain Operations Reference-model (SCOR) developed by the Supply Chain Council [14] SCOR is a process reference model that has been developed as the cross-industry standard diagnostic tool for supply chain management. SCOR enables users to address, improve and communicate supply chain management practices among all interested parties. It models five types of operations: Plan, Source, Make, Deliver and Return [15].

The Design Chain Operations Reference-model (DCOR) [16]. DCOR is a standard description of a product design process that provides companies with a well-recognised language to communicate with their customers and suppliers.

These frameworks propose different solutions to the Supply Chain Management problem. But there is a lack of knowledge about how to apply them to all supply chain interoperability problems. AIF does not provide a methodology on how to solve interoperability problems in the several phases of an improvement project [17]. GSCF and SCOR are more focused on the integration of the supply chain business processes than on their interoperability. DCOR is oriented to improving only the design processes inside the supply chain without considering other supply chain business processes.

\section{Supply Chain Interoperability Framework}

In order to carry out an interoperability supply chain development and implementation project successfully, while at the same time reducing the degree of complexity, it would be a great aid to be able to use a framework that defines, among other things, the tasks to be performed, the techniques to be used, the modeling languages for representing the different domains and the technological infrastructure that allows the supply chain to be interoperable.

With a view to solving this problem of a lack of such frameworks for SC, since 2008 the Integration and Systems Re-engineering (IRIS) Group at the Universitat Jaume I in Castellón (Spain) has been working on a project entitled "eSISA: Interoperability solutions for the food industry". The aim was to develop and validate a framework (called SCIF-IRIS) that allows a SC to be interoperable. Different enterprises (including producers, manufacturers, carriers, packers and ICT) related with the food sector took part in the eSISA project. 
First of all, the literature dealing with this line of research was reviewed (especially works related with interoperability and the food supply chain). This enabled us to gain a clearer vision and better understanding of the topic. An initial version of the framework was then developed based on the literature review and the previous research and practical work of the members of the IRIS group in both interoperability projects and on SCM and integration. This initial version of the SCIF-IRIS was then applied to the enterprises that collaborated in the eSISA project with the aim of improving the interoperability of their SC while at the same time enriching and validating the framework. The final SCIF-IRIS framework is made up of six dimensions (see Figure 1): Semantic Alignment, Models and Modeling Languages, Techniques, Technology, Interoperability Measurement System and Methodology. The Methodology dimension is the axis of the framework and represents the life cycle of the collaborative network. In the following subsections, each dimension of the SCIF-IRIS is explained.

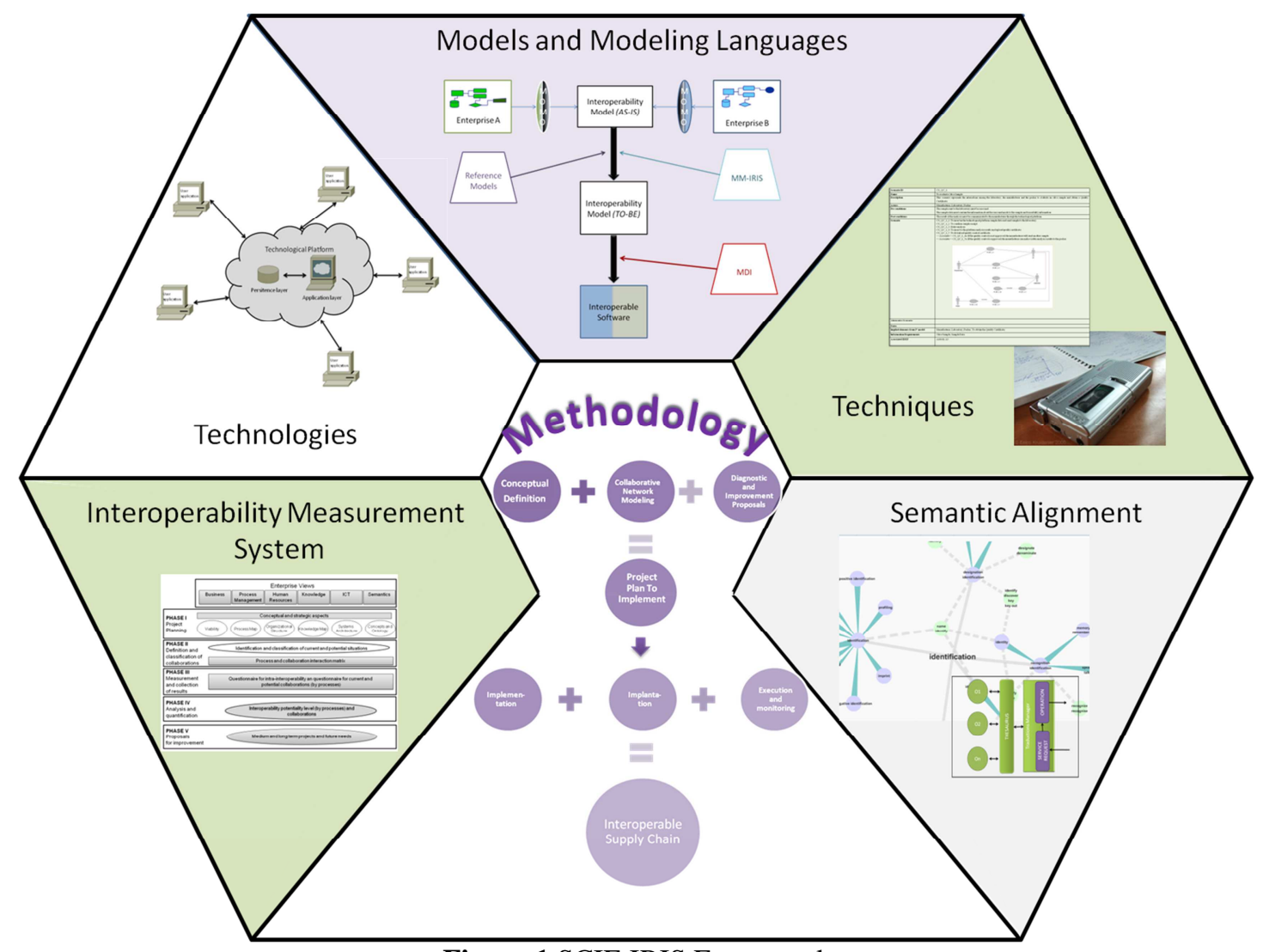

Figure 1 SCIF-IRIS Framework

\subsection{Semantic Alignment}

Semantic Alignment is the method that is proposed in the SCIF-IRIS to resolve the semantic and syntactic conflicts that may arise between the terms used by the participants. It involves the use of a technological platform that includes a thesaurus [18] and a set of ontologies, implemented using Protégé [19]. The difference between a thesaurus and an ontology is that the thesaurus does not contain any axioms that allow any kind of automatic reasoning to be performed.

The thesaurus is a hierarchical taxonomy in which the terms used in the SC are classified. The creation of the thesaurus makes it possible to resolve semantic conflicts and to characterize the sector in which the SC is created, thereby making it easier to set up future collaborative networks in the same sector. A semantic conflict is produced when two lexically identical terms have different meanings. A set of concepts that are associated to one or more terms are classified in the taxonomy and each term is associated to the participants that use it to designate the concept to which it is associated. Left-hand side of Figure 2 shows the structure proposed by the SCIF-IRIS for the taxonomy of the thesaurus. The content of the thesaurus depends on the sector to which the SCIF-IRIS is being applied. The set of 
concepts shown in right-hand side of Figure 2 is proposed as a starting point for the taxonomy. Model Morphism (MoMo) [20] can be applied in order to obtain the concepts of the thesaurus from the enterprise models, if they exist. In this case MoMo is applied in the following way: a set of concepts that denote the elements of a model are extracted from a model of one of the enterprises. Each element in each enterprise model is then associated with a concept and that concept is also linked to the terms with which it is designated in the different business models and by the participants that use them.

On the other hand, a syntactic conflict occurs when different syntactic values are assigned to two equivalent terms (for example, a product code that one participant represents using numbers while another uses a series of characters).

Creating the axioms to resolve the syntactic conflicts of all the terms used by the actors for all the relationships between all the actors is a task that grows exponentially with the number of actors. In this case, it is necessary to create an ontology for each collaboration that includes only the terms that are used in it, so that they are compatible and can be processed on different computer systems. The structure of the axioms of the ontology is as follows: Let $\mathrm{S}$ be an interoperability scenario. Let $\mathrm{T} 1$ and $\mathrm{T} 2$ be two series of terms that need to be compatible so that $\mathrm{S}$ can be performed. There is an axiom in the ontology like this: T1 mustBeCompatibleWith T2 using op, where op is the operation to be carried out on the terms so that they become compatible. In general they will be conversions between different types in order to resolve possible syntactic conflicts. The reason for using ontologies is to ensure that the implementation of the SC is independent of the participants. Thus, if one participant changes or a new participant is introduced, only the semantic alignment will have to be changed to allow it to be incorporated into the SC.

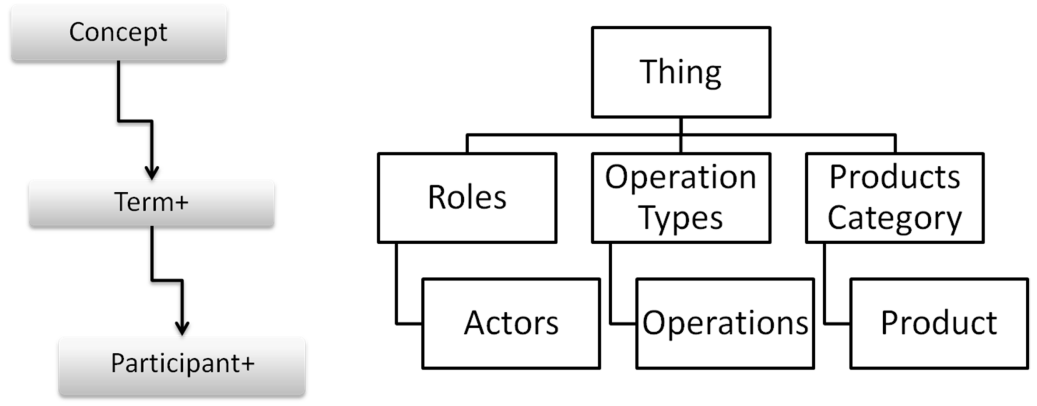

Figure 2 Structure of the Thesaurus

\subsection{Models and Modeling Languages}

The dimension Models and Modeling Languages consists of: (1) a set of reference models of interoperability best practices, which must be taken into account in order to make it easier to redesign the SC bearing in mind how enterprises interoperate in other networks; (2) the enterprise models of the organizations participating in the SC that collect knowledge about different aspects of those enterprises, such as products, services, organization, and so forth; (3) modeling languages which will be used to represent the interoperability model, that is to say, the model that describes the collaborations within the supply chain; (4) application of the MoMo technique to generate transformations and correspondences among the original enterprise models and the interoperability model; and (5) the Model Driven Interoperability (MDI) technique [21] to generate the interoperability software from the interoperability model. The languages that are used to represent the SC interoperability model within the SCIF-IRIS are:

- I* [22]: which makes it possible to model the participants and the objectives that connect them in the supply chain. Each participant has a set of goals to fulfill, and there is a relationship among two or more actors if the goal is achieved through collaboration among the related participants.

- IDEF0 [23]: which is used to model the processes to be performed through the collaborative network. Even though, there are other business process modeling languages, we choose IDEF0 because it is easy to read and understand for people that are not familiarized with modeling languages.

- UML [24]: which is used to model the interactions among the participants and the technological platform, implemented as a support for the operation of the collaborative network. 


\section{3}

\section{Techniques}

The following techniques are used in the SCIF-IRIS to create the supply chain:

Extraction of information: In order to extract information directly from the actors, we propose the use of Open-Ended Interviews [25], in which the interviewer poses a question and then the interviewee answers.

Collaborative Work Sessions: In collaborative work sessions participants in the network meet to share the progress that has been made in the SC, resolve possible conflicts and coordinate the performance of the next tasks to be carried out. The fact that representatives from the whole supply chain participate helps to ensure that: (1) all the participants feel responsible for the success of the project, since they were all involved in the decisions that were made about how to do it and, therefore, (2) they all feel comfortable during the creation of the network because they are all aware of exactly what stage in the process of creation is being carried out at any given time and how the tasks that they have performed actually contribute to the final outcome.

Templates: Within the SCIF-IRIS a series of templates are used to represent the collaboration scenarios among participants and to define the collaboration processes in a homogenous manner.

\subsection{Technology}

Within the Technology dimension, two categories can be distinguished. The first covers the computer tools that allow the Methodology included in SCIF-IRIS to be carried out, while the second includes the technologies that allow the processes associated to the SC to be executed and monitored. In the first category, word processors are used to write the documents; TAOM4E [26] is utilized for modeling with $I^{*}$; case tools are employed for IDEF0; Eclipse [27] is used as the development platform; Java [28] serves as the programming language; and Protégé is the ontology management tool. Within the second category the chief means of communication is the Internet, since it allows data to be transferred directly, rapidly and securely [16]. Furthermore, the Service Oriented Architecture (SOA) [29] is used for software development because it can be integrated easily into the Internet.

\subsection{Interoperability Measurement System}

An interoperability measurement system is a decision support system that uses a set of indicators to analyze the capacity of enterprises to interoperate. It is a performance measurement system but within the area of interoperability. In the SCIF-IRIS, the maturity model MM-IRIS [30] is used as the interoperability measurement system. MM-IRIS includes a set of parameters and a methodology that guides the evaluation of the level of enterprise maturity in terms of interoperability. As the level of maturity in interoperability is not homogeneous throughout the whole enterprise, MM-IRIS defines six different views of the enterprise that allow detection of the levels attained in each case, i.e. Business, Process Management, Knowledge, Human Resources, ICT and Semantics.

\subsection{Methodology}

The main dimension of the SCIF-IRIS is a step-by-step methodology which acts as a guide throughout the interoperability improvement project, and which uses components from the other dimensions as supports in its different phases. Table 1 shows the methodology that is proposed within the SCIF-IRIS. It is arranged in sequential phases and the different tasks and activities to be carried out, how to do them and who should participate in them are indicated for each phase. Next, are explained the roles of the participants in the execution of the methodology:

Promoter (P): This represents the promoter of the interoperability of the SC. It is the person who proposes the interoperability of the SC so as to be able to satisfy a series of needs in the business model of the enterprise that he or she represents.

Actors' Representatives (AR): This refers to the set of people who work in the enterprises involved in the supply chain. These actors make up the Collaborative Network Management Group (CNMG) and 
participate in the strategic tasks of the methodology, as well as the validation and verification of the technological platform developed to support the supply chain.

Domain Experts (DE): This refers to the set of people who are closely related with the sector that the supply chain belongs to and who have a holistic view of the collaborations that are carried out. They must be people who do not work in the enterprises in the supply chain and who offer a neutral point of view about the collaborations that are carried out.

Requirements Engineers (RE): This refers to people who are specialized in requirements elicitation and guide the development of the technological platform which must support the supply chain. This role has been included as a participant because requirements elicitation techniques have been applied to obtain the characteristics of the interoperable supply chain [31]. These techniques are used to ascertain users' needs and to make a documentary record of them so that they can be shared among the different actors. The aim of the analysis and requirements elicitation task is to obtain knowledge about the final users' needs, surroundings and the rationale driving the development or implementation of a computer system [32]. Furthermore, it becomes more complex as the typology of the final users grows, since different perspectives have to be taken into account so that the different needs can be put together under a single technological platform that satisfies them all [33].

Developers and testers (DT): This refers to the people responsible for developing and testing the technological platform.

Users (U): This refers to the set of users who are going to make direct use of the supply chain.

Table 1 Methodology of SCIF-Framework

\begin{tabular}{|c|c|c|c|c|}
\hline Phase & Tasks & Activities & How & Who \\
\hline \multirow{6}{*}{$\begin{array}{l}\text { Conceptual } \\
\text { Definition }\end{array}$} & \multirow{4}{*}{$\begin{array}{l}\text { Strategic } \\
\text { Definition }\end{array}$} & $\begin{array}{l}\text { Collaborative Network } \\
\text { definition }\end{array}$ & $\begin{array}{l}\text { Collaborative work } \\
\text { sessions with partners }\end{array}$ & $\begin{array}{l}\text { P, DE, RE } \\
\text { CNMG, }\end{array}$ \\
\hline & & $\begin{array}{l}\text { Diagnosis of the } \\
\text { situation }\end{array}$ & MM-IRIS & RE, CNMG \\
\hline & & Goals definition & $\begin{array}{l}\mathrm{I}^{*}, \text { Open-Ended } \\
\text { Interviews, Scorecard }\end{array}$ & $\begin{array}{l}\text { CNMG, } \\
\text { DE, RE }\end{array}$ \\
\hline & & Project Plan & Project Memory & $\begin{array}{l}\text { DE, RE } \\
\text { CNMG, }\end{array}$ \\
\hline & \multirow[b]{2}{*}{$\begin{array}{c}\text { Collaborative } \\
\text { Process } \\
\text { Definition }\end{array}$} & $\begin{array}{l}\text { Responsibility } \\
\text { definition }\end{array}$ & $\begin{array}{l}\text { Collaborative work } \\
\text { sessions with } \\
\text { partners, Templates }\end{array}$ & $\begin{array}{l}\text { DE, RE } \\
\text { CNMG, }\end{array}$ \\
\hline & & $\begin{array}{l}\text { Relationships among } \\
\text { collaborative processes } \\
\text { and internal processes }\end{array}$ & Templates & $\begin{array}{l}\text { DE, } \\
\text { CNMG, RE }\end{array}$ \\
\hline \multirow{3}{*}{$\begin{array}{l}\text { Collaborative } \\
\text { Network } \\
\text { Modeling }\end{array}$} & $\begin{array}{c}\text { Global Process } \\
\text { Modeling } \\
\end{array}$ & IDEF0 Model & $\begin{array}{l}\text { IDEF0 Modeling } \\
\text { Tools }\end{array}$ & $\mathrm{RE}, \mathrm{CNMG}$ \\
\hline & $\begin{array}{c}\text { Semantic } \\
\text { Alignment }\end{array}$ & $\begin{array}{l}\text { Develop a thesaurus and } \\
\text { ontologies }\end{array}$ & $\begin{array}{l}\text { Documentation } \\
\text { review }\end{array}$ & $\mathrm{DE}, \mathrm{RE}$ \\
\hline & $\begin{array}{l}\text { Collaborative } \\
\text { Scenarios } \\
\text { Modeling }\end{array}$ & $\begin{array}{l}\text { Definition of the } \\
\text { collaborative processes } \\
\text { as collaborative } \\
\text { scenarios (AS-IS) } \\
\end{array}$ & $\begin{array}{l}\text { Templates, } \\
\text { UML }\end{array}$ & RE, CNMG \\
\hline \multirow{3}{*}{$\begin{array}{c}\text { Diagnosis and } \\
\text { Improvement } \\
\text { Proposals }\end{array}$} & \multirow{3}{*}{$\begin{array}{l}\text { Measurement of } \\
\text { the ability to } \\
\text { interoperate and } \\
\text { interoperability } \\
\text { projects }\end{array}$} & Knowledge view & \multirow[t]{3}{*}{ MM-IRIS } & \multirow[t]{3}{*}{ RE, CNMG } \\
\hline & & Process view & & \\
\hline & & HR view & & \\
\hline
\end{tabular}




\begin{tabular}{|c|c|c|c|c|}
\hline & definition & ICT view & & \\
\hline & $\begin{array}{l}\text { Collaborative } \\
\text { Scenarios } \\
\text { Modeling }\end{array}$ & $\begin{array}{l}\text { Definition of the future } \\
\text { collaborative processes } \\
\text { as collaborative } \\
\text { scenarios (TO BE) }\end{array}$ & Templates, UML & RE, CNMG \\
\hline \multirow{4}{*}{ Implementation } & \multirow{4}{*}{$\begin{array}{l}\text { Interoperability } \\
\text { projects } \\
\text { implementation }\end{array}$} & Business re-definition & $\begin{array}{l}\text { Managers' } \\
\text { experience } \\
\text { Consultancy }\end{array}$ & \multirow[t]{4}{*}{$\begin{array}{l}\text { RE, DT, U, } \\
\text { CNMG }\end{array}$} \\
\hline & & Process re-engineering & $\begin{array}{l}\text { Reference Models } \\
\text { Workers' experience } \\
\text { Consultancy }\end{array}$ & \\
\hline & & HR management & $\begin{array}{l}\text { Managers' } \\
\text { experience } \\
\text { Consultancy }\end{array}$ & \\
\hline & & Platform Development & SOA & \\
\hline \multirow[t]{2}{*}{ Implantation } & $\begin{array}{l}\text { Collaborative } \\
\text { Work Sessions }\end{array}$ & $\begin{array}{l}\text { Sessions to explain to } \\
\text { users how to use the } \\
\text { Technological Platform }\end{array}$ & $\begin{array}{l}\text { Collaborative Work } \\
\text { Sessions }\end{array}$ & $\begin{array}{l}\text { RE, DT, U, } \\
\text { CNMG }\end{array}$ \\
\hline & $\begin{array}{c}\text { Platform } \\
\text { implantation }\end{array}$ & Commissioning & Ad hoc applications & $\begin{array}{l}\text { RE, DT, } \\
\text { CNMG }\end{array}$ \\
\hline $\begin{array}{l}\text { Execution and } \\
\text { monitoring }\end{array}$ & $\begin{array}{l}\text { Monitoring } \\
\text { System }\end{array}$ & $\begin{array}{l}\text { Definition of indicator } \\
\text { about the performance } \\
\text { of the collaboration } \\
\text { network }\end{array}$ & $\begin{array}{l}\text { Technological } \\
\text { platform, special } \\
\text { tools for creating } \\
\text { reports [34] }\end{array}$ & DT, U, RE \\
\hline
\end{tabular}

\subsubsection{PHASE I: Conceptual Definition:}

The conceptual definition of the SC is divided into two activities: the strategic definition of the SC and the definition of the collaborative processes. These two activities are outlined in the following subsections.

Strategic Definition: This activity is started by the network promoter and its outcome is the definition of the Project Plan. Each of the tasks to be carried out within this activity is explained in the following:

Collaborative Network Definition: The first task to be performed when carrying out any project is to define the project plan [35]. However, since different enterprises are involved in the supply chain, the first task is to define the actors in it so that they all have a say in defining the project plan and the decisions that are made are agreed on by all. The activities to be carried out are as follows:

- Promoter: The promoter defines the mission of the supply chain interoperability and obtains authorization to implement it from the enterprise in which he or she works.

- To establish the collaborative network participants and the work team (CNMG). They are led by a project coordinator chosen from among the people with the greatest specific weight and experience inside the partner enterprises and a collaboration agreement is signed. The collaboration agreement must contain a description of the resources that are going to be allocated by each participant in order to define the interoperability supply chain and the initial budget.

- To contact domain experts.

- To define the mechanisms that will be used to communicate the evolution of the interoperability supply chain project.

- To define the characteristics of the interoperability supply chain, such as the topology of the SC or its stability or heterogeneity, among others. The topology is represented using a conceptual map, which is a graphical representation of the network participants where the connections among them are represented by arrows. 
- To engage a group of requirements engineers who will help the CNMG in the task of modeling and with the extraction of the needs of the partners to be supplied by the SC.

Diagnosis of the situation: The strategic aspects of the enterprises in the SC that have repercussions on their capacity to establish collaborations must be measured and evaluated. For instance, it is necessary to measure whether they follow Sustainability and quality policies, their capacity/willingness to adapt to organizational, technological and social changes, their Strategy as regards the use of technologies as a support to aid in collaborations with other enterprises, their Policies with respect to the use of technological and information standards or their Policies on the (social, technological, etc.) evaluation of possible partners prior to establishing relations. This is achieved using the parameters from the Business view of MM-IRIS.

Goals definition: The next activity is to define the goals to be achieved for each participant in order to reach the mission statement of the supply chain interoperability. This task is performed by the Domain Experts and Requirements Engineers using Open-Ended Interviews. For each connection on the conceptual map of the supply chain interoperability, they must ask the CNMG what specific goals are to be achieved in the collaborations in order to help accomplish the mission of the SC. This task concludes with the documentation of the goals. The SCIF-IRIS uses the Tropos Methodology [36] with I* and TAOM4E to identify goals. These goals are later set out on an interoperability goals map. On this map the goals are arranged in the six perspectives proposed by the MM-IRIS and their hierarchical relations are established, in a similar way to the procedure used in a strategic map in a performance measurement system.

Project Plan: The last task is the elaboration of the Project Plan. The project plan is a document drafted with the general consensus of the CNMG where all the information obtained in the previous tasks and the action plan to be followed in the future must be specified. The document must contain: Mission, Vision and Values of the SC; the agreement letters signed by the actors' representatives on behalf of its company; SC Topology and SC characteristics; goals definition and strategic map of collaboration goals; estimation of initial budget; results of the diagnostic of the current situation and action plan: the action plan is elaborated according to the SCIF-IRIS phases.

Collaborative Process Definition: The aim of this task is to define the collaborative processes to be carried out within the SC. To do so, the models used internally by the enterprise, if any, are analyzed and a series of collaborative work sessions are held in which the DEs and REs must guide the CNMG in defining the collaborative processes that have to be carried out in the SC in order to reach the specific goals set out in the project plan. The job of the DEs and REs is to make the CNMG think about which processes have an effect on whether the objectives of the SC are fulfilled or not. Then, the relationships between the collaborative processes and the internal processes of each participant must be described. An internal process is considered to be one that only a single participant is involved in.

The information obtained in this task is represented using the template shown in Table 2. The template makes it possible to define the collaborative processes in terms of the participants (first column) and the internal processes of those participants with which the collaborative process is related and the description of the relationship. In addition, the definition of the inputs and outputs of the collaborative process and those responsible for them are also included in the template.

Table 2. Template for Collaborative Process Definition

\begin{tabular}{|l|l|l|}
\hline Collaborative Process: & Name \\
\hline \multirow{2}{*}{ Participant 1 } & Internal Process 1 & Relationship description \\
\cline { 2 - 3 } & $\ldots$ & $\ldots$ \\
\hline \multirow{2}{*}{ Inputs } & $\ldots$ & $\ldots$ \\
\hline Outputs & Input 1 & Actor Responsible \\
\cline { 2 - 3 } & $\ldots$ & \\
\hline
\end{tabular}

\subsubsection{PHASE II: Collaborative Network Modeling}


The second phase of the SCIF-IRIS methodology is to model the collaborative processes, that is to say, the interoperability models defined in the templates, their semantic alignment and the design of their collaboration scenarios. This task must be carried out in collaboration with the requirements engineers, who are usually experts in the use of models to represent processes. This phase consists of three activities: Global Process Modeling, Semantic Alignment and Collaborative Scenarios Specification.

Global Process Modeling: This activity consists in the creation of a global model that includes all the internal and collaborative processes involved in accomplishing the mission of the network from a holistic point of view as they are performed at the present time (AS-IS). In this subsection there are two alternatives. If the enterprises already have models of their internal and collaborative processes, MoMo techniques can be used to establish a correspondence between those models and thus avoid having to create new models. Otherwise, it will be necessary to generate models of the current situation. In this case, IDEF0 is proposed as the method with which to represent the processes, since it is easily understood by users who are not experts in the use of models [37]. The process can also be modeled regardless of who carries it out and the different activities can be connected by means of procedure calls. At this point, the first doubt to arise concerns the number of explosions to be represented with IDEF0. On this issue it must be borne in mind that the level of precision must be high enough to be able represent the interactions of the supply chain with the internal processes defined in the templates shown in Table 2.

The aim of this phase is to determine the point during the overall process at which the interactions among the elements of the SC take place, since the activities that are carried out in the interactions will be used as the basis on which to accomplish the goals that were identified in the first phase. On finishing the model, two questions must be checked: (1) whether the human resources (mechanisms in IDEF0 terminology) associated to each collaborative-type process coincide with those defined in the templates for the definition of processes; and (2) whether the internal processes related to the collaborative processes of the IDEF0 model coincide with the ones that were set out in the templates for defining collaborative processes. Should either of the two questions fail to coincide in the templates and the model, both of them will have to be reviewed and any changes that might be necessary must be introduced.

Semantic Alignment: At this point the first part of the semantic alignment is performed, the thesaurus. From now on, the language to be used in the rest of the activities will consist mainly in the concepts defined within it. The creation of the thesaurus must be guided by the domain experts and based on the enterprise models. Yet, the enterprises might not have any models. In this case, this task can be performed by reviewing the documentary material concerning the sector on which the collaborative network is working and extracting the nouns that represent it. Generally speaking, the documentary material to be reviewed consists of the external regulations or laws regarding the sector, the internal regulations of the participating enterprises and the documents generated throughout the process of implementing the methodology. Moreover, the use of an ontology that contains axioms like those described in 3.1 is recommended to resolve semantic and syntactic conflicts.

Collaborative Scenarios Specification: The next step is to specify the collaboration scenarios in detail [38]. If the enterprises already have detailed models of their internal and collaborative processes, MoMo techniques can be used to establish a correspondence between those models and thus avoid the need to create new models. Otherwise, it will be necessary to generate new models using the IDEF0 technique. These models must reflect the way in which the participants in the network currently collaborate. For each collaboration process that is defined, one or more collaboration scenarios will be specified; these can be extracted from the global model using the following heuristics:

Let there be two processes $p_{1}$ and $p_{2} . p_{1}$ and $p_{2}$ are linked if an output of $p_{1}$ is used as an input, control or mechanism of $p_{2}$.

A collaboration scenario exists between two processes $p_{1}$ and $p_{2}$ from the IDEFO model if, and only if, $p_{1}$ and $p_{2}$ are linked and there is a mechanism $m_{1}$ of $p_{1}$ that represents an actor (either a human or a computer system) and a mechanism $m_{2}$ that represents an actor (either a human or a computer system) and $m_{1}$ is different from $m_{2}$ and belongs to different participants.

A collaboration scenario exists if two different mechanisms that represent an actor (either a human or a computer system) and belong to different participants participate in the same IDEFO process.

Applying the first heuristic produces a list of pairs of activities in which some collaboration is produced. With the second one, collaborative processes are obtained. Note that the result of applying the 
second heuristic should be the collaborative processes defined in the previous phase. However, applying the first one makes it possible to detect other points in which collaborations take place and which, if the network is very extensive, may have gone unnoticed when the collaborative processes were being defined. Furthermore, it also allows the points of potential collaboration among participants to be identified.

The next step is to represent these collaborations as collaboration scenarios. Collaboration scenarios are a textual and graphical representation of the collaborations that take place among the actors and they allow additional information about the scenarios to be included. Such information includes the preconditions or the post-conditions of the collaborative process. The SCIF-IRIS recommends using the template shown in Table 3. for the textual representation. This template is based on the Requirements Elicitation Methodology [39].

Table 3. Template for Collaboration Scenarios Specification

\begin{tabular}{|l|l|}
\hline Scenario ID & Collaboration scenario identification number. \\
\hline Name & Name assigned to it. \\
\hline Description & Description of the scenario. \\
\hline Actors & Actors involved in it. \\
\hline Pre-conditions & Conditions that must be fulfilled before the scenario is executed. \\
\hline Post-conditions & Conditions that must be fulfilled after the scenario has been executed. \\
\hline Scenario & $\begin{array}{l}\text { Textual and graphical representation of the scenario (employing UML use } \\
\text { cases). }\end{array}$ \\
\hline Alternative Scenario & Other possible representation of the scenario (described in text form). \\
\hline Notes & Considerations to be taken into account. \\
\hline I* model elements & Elements in the involved objectives diagram. \\
\hline IR & (Information Requirements) Data needed to execute the scenario. \\
\hline Associated IDEF & $\begin{array}{l}\text { Activities represented by means of IDEF0 associated to the use case. It may be } \\
\text { specific to a particular use case or cover several of them. }\end{array}$ \\
\hline
\end{tabular}

\subsubsection{PHASE III: Diagnostic and Improvement Proposals}

The third phase is to diagnose the ability of the participants in the SC to interoperate and identify the improvement projects. This phase consists of two activities: Measurement of the ability to interoperate and Collaborative Scenarios Specification (TO-BE).

Measurement of the ability to interoperate: Using the methodology and the parameters proposed in MM-IRIS makes it possible to measure and evaluate the level of interoperability in each collaboration within the supply chain, taking into account aspects related to Business, Process Management, Knowledge, Human Resources and ICT. Examples of the aspects that are measured include: for the Business view, whether there is a policy of using standards. For the Process view, whether the processes are identified, documented, modeled or planned. For the Knowledge view, whether there is a Collaborative Knowledge Management System. For the HR view, whether there is a well-defined and documented structure with assigned roles and flexibility to exchange jobs. For the ICT view, whether it is easy to develop ad hoc applications to connect the participants with the technological platform of the SC.

This diagnosis is then used to define the improvement projects and they are arranged in order of priority using a feasibility study that takes traditional cost/benefits into account, although organizational, technical and operational aspects should also be considered.

Collaborative Scenarios Specification (TO-BE): The second activity is the specification of the future collaborative scenarios, the interoperability models, taking into account the AS-IS model, the interoperability improvement projects and the reference models of the second dimension of the SCIFIRIS. Specification is performed using the same templates as those used for the AS-IS model (Table 3, but now the actor Technological Platform appears in all the scenarios. 


\subsubsection{PHASE IV: Implementation}

The fourth phase of the SCIF-IRIS is the development of projects to improve the interoperability of the supply chain. These projects may involve, for example, redefining strategic aspects, the culture, the mission, the vision, the values or the economic, social and environmental policies of the organizations (Business View); redesigning the processes carried out by the enterprise, identifying possible ways of improving work methods (and therefore improvements to productivity and cost reduction) based on an efficient interaction with the processes of other enterprises, with a special emphasis on processes that generate sustainability (Process View); restructuring human resources in order to adapt them to the new situation, bearing in mind that the employees' skills, abilities, roles, culture, collaborative capacity, and so on can improve interoperability (HR View); or the development of the technological platform, which must provide automatic interconnection among the applications, data and communication components that are needed to support the execution of the collaborations scenarios that were modeled in phase II (ICT View).

Implementation of the technological platform must be based on architectures that can be integrated into the Internet easily, such as the SOA, and utilize a development approach that is guided by previously obtained models (MDI). Left-hand side of Figure 3 shows the architecture of the technological platform based on the SOA structure. This architecture has four layers: (1) Persistence layer: This is the layer where the data needed by the supply chain are stored. It can be implemented using any relational database management system. A minimum requirement of the database is that it should be designed in such a way as to allow storage of both the inputs and the outputs from the collaboration scenarios that were specify in phase II. (2) Application layer: This is the layer that implements the collaborative processes. In an SOA setup, they are Web services that can be consumed by remote clients and there will be at least one web service for each collaboration scenario; this service will allows the exchange of information needed by actors to be able to collaborate or, if the collaboration can be automated, to perform the collaborative tasks and send the results to the actors involved. (3) Communication layer: The application layer must take into account the Semantic Alignment dimension so as to be able to communicate with each actor in a way that is coherent with the terminology that he or she uses. For this reason a communication layer has been included within the application layer. Right-hand side of Figure 3 shows the architecture of this communication layer and it has the following components. Thesaurus: This is the representation of the taxonomy produced in phase II. O1...On: These are the ontologies that contain the axioms and the terms needed to resolve the syntactic and semantic conflicts. Translations Manager: Receives the requests from Service Request and invokes the Operation component. Operation: Given an operation and a set of terms, it runs the operation and returns the result obtained from running it. Service Request: Given a set of terms, the ID number of an axiom and the ID number of a collaboration scenario, it retrieves the operation to be carried out on the terms from the corresponding ontology and invokes the operations module. (4) Users' Application Layer: The layer that allows users (which may be both human and other systems) to have access to the services offered by the technological platform.

The last task in this phase is to generate the documents concerning the use of the services that enable the collaboration to be carried out. 

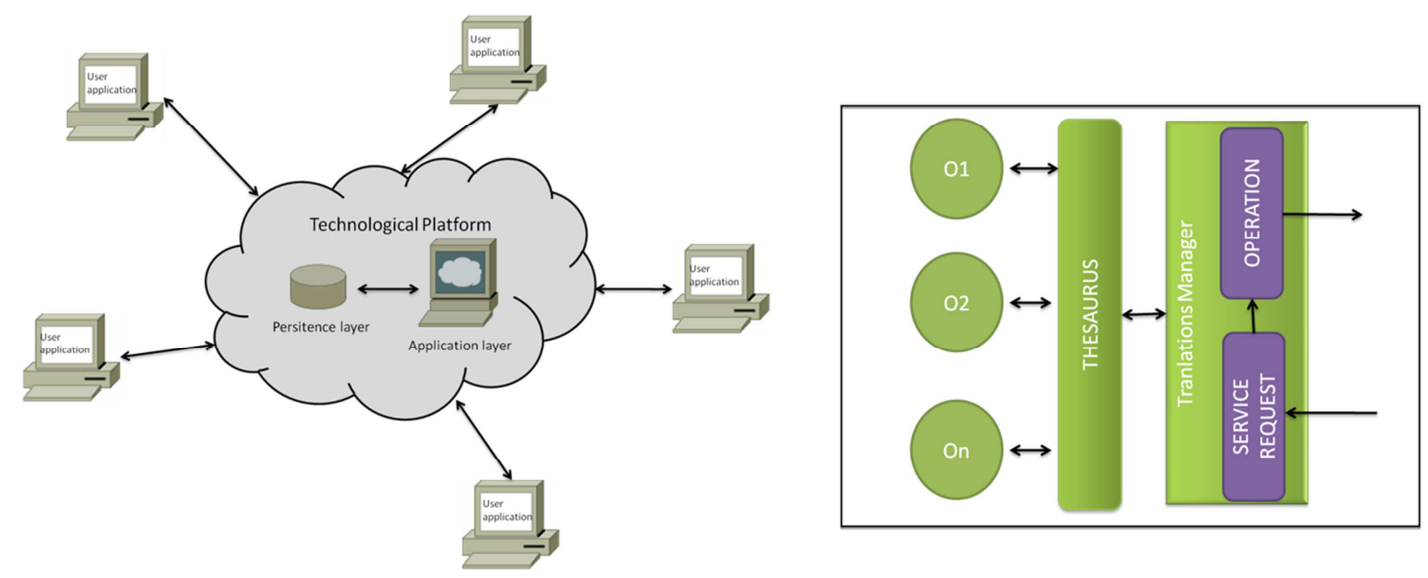

Figure 3 Architecture of the Technological Platform

\subsubsection{PHASE V: Implantation}

Once the interoperability projects have been developed, they must be implanted. At this point collaborative work sessions must be held so that users can be told about the new way the enterprise works and how to use the technological platform. Finally, the platform is started up and the computer systems of the participating enterprises are connected using ad hoc applications.

\subsubsection{PHASE VI: Execution and monitoring}

The methodology ends by including a continuous improvement system that identifies new requirements related with the interoperability of the SC.

\section{Case Example}

This section describes a case example in which the SCIF-IRIS is applied. The case example focuses on the collaboration of different enterprises in order to produce table olives. Because they are enterprises in the agro-food sector, ensuring quality, hygiene and safety at each stage of the food production chain is essential, not only in this case but around the world, both in industrialized and in developing countries. Furthermore, the crises involving or related to foodstuffs over the last decade, such as mad cow disease, triggered a change of direction in consumer protection and food safety policies. The purpose of this case study was to improve the collaboration among enterprises involved in the production of table olives in Spain in order to strengthen and stabilize the collaborations within the supply chain so that the information generated in the process of transforming the raw material (in this case olives) is always available. By so doing, should there be any kind of problem, such as a contaminated can of olives, it is possible to trace the path taken by that can and what batches may be contaminated, instead of having to withdraw all the goods from points of sale.

In order to improve collaborations, a technological platform was developed for a supply chain made up of a set of enterprises with very different profiles and which find it difficult to collaborate effectively with one another. This reduced the risk of the table olives being affected by some kind of food hazard. In the following, the profiles of the different enterprises involved in the case study are outlined.

Producer: This is the grower, i.e. the actor responsible for collecting the olives from the groves and delivering them to the manufacturer's facilities.

Manufacturer: This is the processing plant responsible for turning harvested olives into olives that are ready to be packed. In this case this is the network promoter.

Carrier: This is the actor that performs operations involving collecting logistic units of the product from one actor and delivering them to another.

Packer: This is the actor who is responsible for carrying out the packing processes in order to prepare finished product units that are ready to be marketed. 
Dealer: The actor in charge of distributing the logistic units of packed table olives to the points of sale to the final consumers.

Supplier (linked): A supplier who is subcontracted by the manufacturer to process the olives.

Supplier 1 (laboratory): The actor responsible for carrying out quality control analyses on the batches of processed and packed olives in order to ensure the product meets the health standards, by guaranteeing that the olive from the groves is free of any kind of phytosanitary defect or that the packed olives have undergone the processes of pasteurization/sterilization in a satisfactory manner.

Supplier 2 (Auxiliary materials/ingredients): This actor is responsible for supplying the auxiliary materials needed in the curing processes (e.g. lye), the packing processes (e.g. the brine components), as well as the ingredients to be used in manufacturing the packed product (e.g. anchovies, red peppers).

Supplier 3 (Packing): This is the actor who provides the packing that the finished product will be put into, and may consist of cans, jars, cartons or boxes, in their different formats and materials.

Before creating the supply chain, the participants already collaborated on a local scale, that is to say, each actor only collaborated with the actors with whom they had a direct relationship. Thus, information about the quality controls carried out by the manufacturer was not available to the dealer. Through the technological platform developed for the SC, the actors are linked to each other by means of the network and can share the food safety management standards, everybody has access to the information concerning a product, and production processes become transparent. This section explains how the SCIF-Framework was applied in the supply chain. The example focuses on the collaboration with laboratories so that a phytosanitary certificate can be issued to prove that the processed olives comply with health standards.

\subsection{PHASE I: Conceptual Definition}

\section{Strategic Definition:}

Collaborative Network Definition: The conception of supply chain interoperability begins when the manager of the manufacturer's quality control department (in this case the promoter) sees the need to improve interactions with different collaborators in order to ensure the quality of the table olives and defines the mission of the supply chain: "To ensure the transparency of the information regarding the quality controls carried out on the table olive throughout its entire life cycle". Once he or she has been given the go-ahead by the managers of the enterprise, the Promoter contacts the enterprises that they collaborate directly with, i.e. producer, linked supplier, laboratory, auxiliary material supplier and packer. In addition, in this case, the packer proposes that the dealer should also be included, since this is the actor who closes the table olive's life cycle before it reaches the point of sale and the consumers. Once the participants, who represent the CNMG, have been established, they get in contact with the DE, who in this case is represented by the authorities that will certify the quality of the table olive.

The next step is to hold a collaborative work session in which the communication mechanisms to be used in the supply chain are defined, the conceptual map of the actors is created and the characteristics of the supply chain are defined. In the following, the outcomes of each of these tasks are outlined.

Communication mechanisms: For each task that is performed, a deliverable stating the activities carried out in each task must be created and sent in electronic form to each of the participants.

Characteristics of the supply chain: Figure 4 shows the conceptual map of the participants in the SC. The characteristics of the $\mathrm{SC}$ are as follows:

- The supply chain is made up of eight different actors.

- Geographical dispersion: Geographical dispersion occurs on two levels: (1) The actors are located in different physical places; and (2) one actor can have his or her facilities distributed in different locations.

- A high degree of outsourcing: The number of services that are outsourced is undefined. For example, the manufacturer can outsource the fermentation, or it may be part of his or her processes. The supply chain is dynamic and must be ready to make changes in the roles of the actors smoothly and swiftly.

- Different types of collaboration: The health safety management of the table olive is not a process in itself, but instead the result of controlling all the processes that are carried out on the olives, the ingredients, the packing or how they are transported, among other things. In the study case, these processes were grouped in three types: procurement, which is the set of activities that must be carried out to obtain the auxiliary material (ingredients or packing); transformation of the raw material, 
which includes the activities required to transform the olive that comes from the groves into table olives; and quality control. The process of quality control refers to the specific activities that are carried out with the aim of ensuring the quality of the final product. These activities are performed throughout the whole process of transforming the olive and ensure that not only the minimum quality conditions required by law are satisfied, but also those imposed by manufacturers and packers. The first quality control is to check that the olive that is brought from the grove fulfils the business agreement established between the producer and the manufacturer, where parameters are set regarding size or the percentage of defects, among other features. The next control consists in an analysis of a sample of the green olives conducted by a specialized laboratory. The olive is then controlled throughout the fermentation process and, lastly, once it has been packed.

This activity finishes with the engagement of the requirements engineers.

Diagnosis of the situation: The next step is to perform the diagnosis of the current situation. In this case the diagnosis is poor interoperability, since the relationships between different participants are carried out by following tacit agreements, making telephone calls and exchanging documents whose format and contents are not governed by any kind of agreement among the participants. The situation is repeated in all the perspectives, as the collaborating enterprises have not considered the idea of collaborating with the other participants in an effective way until now.

Goals definition: In this case study, the CNMG decided to use the Tropos methodology for this activity. The DE and RE held Open-Ended Interviews with the participants in order to obtain these objectives. The questions that were asked, among others, dealt with the relationships that they had with participating enterprises, why they thought they ought to be in the supply chain and what they should do to favor accomplishment of the mission of the supply chain. Left-hand side of Figure 5 the strategic goals of the supply chain network that were defined following the interviews. Once the objectives of the $\mathrm{CN}$ have been identified, the relationships between the different objectives must be evaluated in order to detect the dependencies among them.

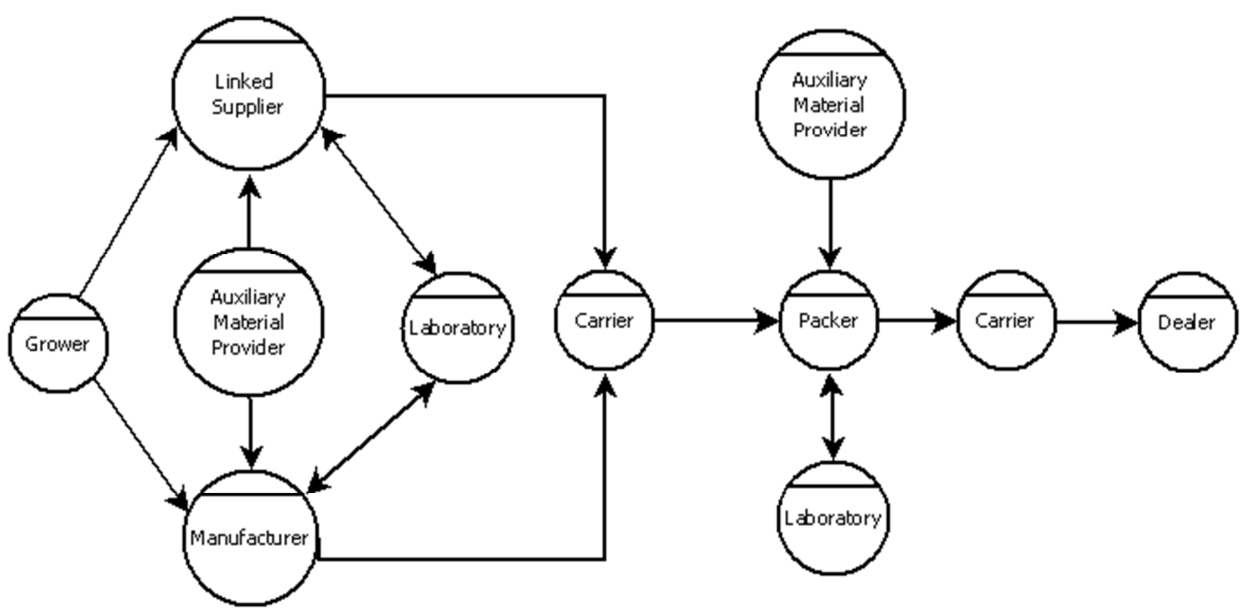

Figure 4 Participants Conceptual Map of the SC

Project Plan: This task concludes with the redaction of the project plan. The document must contain all the information obtained in the Strategy task. 


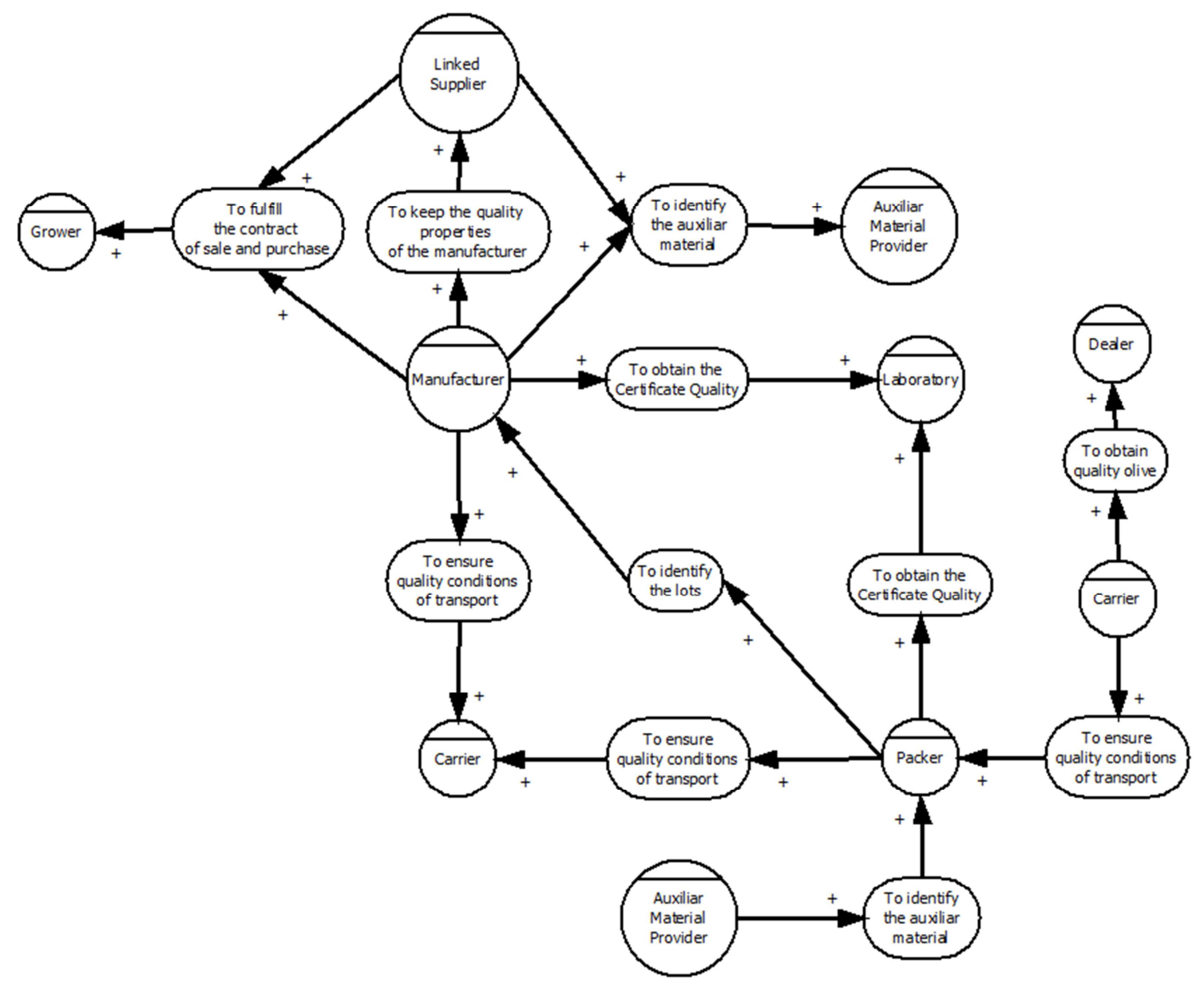

Figure 5 I* Model and Strategic Goals Definition for the SC

Collaborative Process Definition: Table 4 shows the definition of the collaborative process "To evaluate sample". This process is carried out in order to obtain the quality certificate for the processed olive from the manufacturer.

Table 4 To certificate sample Collaborative Scenario definition

\begin{tabular}{|c|c|c|}
\hline \multirow{3}{*}{$\begin{array}{l}\text { Collaborative } \\
\text { Process: } \\
\text { Manufacturer } \\
\text { Link provider }\end{array}$} & \multicolumn{2}{|c|}{ To evaluate olive Sample } \\
\hline & Olive processing & $\begin{array}{l}\text { The olive sample is sent to the laboratory after the } \\
\text { processing. }\end{array}$ \\
\hline & To send Olive & $\begin{array}{l}\text { The olive is sent if and only if the olive has the quality } \\
\text { certificate. }\end{array}$ \\
\hline \multirow[t]{2}{*}{ Packer } & To receive Olive & $\begin{array}{l}\text { The olive is received if and only if the olive has the } \\
\text { quality certificate. }\end{array}$ \\
\hline & To pack olive & $\begin{array}{l}\text { The packing of olives is done if and only if the olive has } \\
\text { the quality certificate. }\end{array}$ \\
\hline Laboratory & To evaluate Sample & The laboratory makes the quality analysis to the sample. \\
\hline \multirow[t]{2}{*}{ Inputs } & Olive sample & Manufacturer / link Supplier \\
\hline & Sample data & Manufacturer / link Supplier \\
\hline Outputs & Certificate quality & Laboratory \\
\hline
\end{tabular}

\subsection{PHASE II: Collaborative Network Modeling}

The first activity in this phase is Global Process Modeling. Figure 6 shows an excerpt from the global model. Specifically, it shows the part related to the collaborative process "To evaluate Sample". 


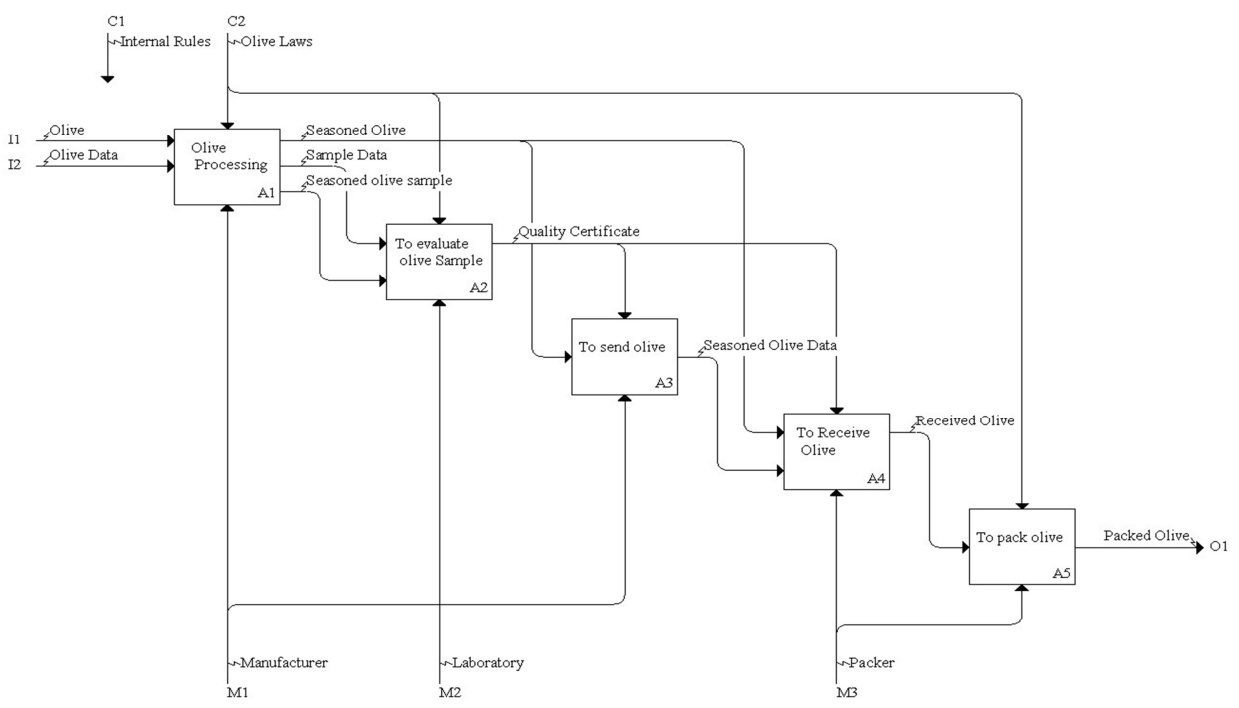

Figure 6 Collaborative Process Model

The next activity is the semantic alignment of the data exchanged in the interaction. A conceptual representation of an excerpt from the taxonomy and the axioms to resolve semantic and syntactic conflicts in the identification of the sample are shown below. It should be noted that GLN stands for Global Location Number [40].

Concept: Traceability Information

Terms: Origin = Producer GLN, Land ID, Date (Manufacturer); Identification: Producer GLN + “-” Land ID + “/” + Date + “-” + Manufacturer GLN (Laboratory)

Axiom: Origin mustBeCompatibleWith Identification using Concatenation

Operation: Concatenation: $=$ Identification $=$ Process $($ Origin $)+$ " ” + Manufacturer GLN

Operation Process(origin) return Producer GLN + “-” Land ID + “/“ + Date

In this case, for the concept Traceability Information, the Manufacturer uses the term Origin, consisting of Producer GLN, Land ID and Date, while the Laboratory uses the term Identification, which comprises the same data plus the Manufacturer GLN. The taxonomy allows us to resolve semantic conflicts between origin and identification and the axiom allows us to resolve syntactic conflicts. It must be pointed out that it is not necessary to create a global ontology for all the business processes executed in all the participants. In this case, we define an ontology for each interoperability point that made the correspondences between the elements of the interoperability point and solves the syntactic and semantic conflicts.

Finally, the collaborative scenarios are specified. By applying the heuristics described in 3.6.2 to the process shown in Figure 6, four collaborative scenarios can be detected: between A1 and A2; between A2 and A3; between A2 and A4; and, between A3 and A4. Each scenario is specified using templates. ${ }^{2}$

\subsection{PHASE III. Diagnostic and improvement proposals}

In this phase the MM-IRIS is applied to measure the ability of enterprises to interoperate. The collaborative scenarios are then specified taking into account the technological platform. Table 5 shows the template for the "To evaluate olive sample" activity (empty rows were avoided).

Table 5 Collaborative Scenario Model for "To evaluate Olive Sample"

\begin{tabular}{|l|l|}
\hline Scenario ID & CS_QC_1 \\
\hline Name & To evaluate Olive Sample. \\
\hline Description & $\begin{array}{l}\text { This scenario represents the interactions among the laboratory, the manufacturer } \\
\text { and the packer to evaluate an olive sample and obtain a Quality Certificate. }\end{array}$ \\
\hline
\end{tabular}

\footnotetext{
${ }^{2}$ It must be pointed out that $\mathrm{C} 1$ control is a control for all the activities.
} 


\begin{tabular}{|c|c|}
\hline Actors & Manufacturer, Laboratory, Packer. \\
\hline Pre-conditions & $\begin{array}{l}\text { The sample sent to the laboratory must be processed. } \\
\text { The sample data must contain the information about the processing of the sample } \\
\text { and traceability information. }\end{array}$ \\
\hline Post-conditions & $\begin{array}{l}\text { The result of the analysis must be communicated to the manufacturer through the } \\
\text { technological platform. }\end{array}$ \\
\hline Scenario & $\begin{array}{l}\text { CS_QC_1_1: To insert the sample data in the technological platform and send } \\
\text { the sample to the laboratory. } \\
\text { CS_QC_1_2: To confirm receipt of the sample. } \\
\text { CS_QC_1_3: Perform the analysis. } \\
\text { CS_QC_1_4: To insert the analysis results into the platform and upload quality } \\
\text { certificate. } \\
\text { CS_QC_1_5: To download quality control certificate. } \\
\text { <<Associate>>CS_QC_1_4a: If the quality control is not approved, the } \\
\text { manufacturer will send another sample. } \\
\text { <<Associate>>CS_QC_1_5a: If the quality control is approved, the } \\
\text { manufacturer can make the analysis results visible to the packer. }\end{array}$ \\
\hline I* model elements & Manufacturer. Laboratory Pa \\
\hline IR & Olive Sample, Sample Data \\
\hline Associated IDEF & Activity A2, A3, A4 \\
\hline
\end{tabular}

\subsection{PHASE IV: Implementation}

The fourth phase is the implementation of the improvements projects in the Business, Process, Knowledge and HR views, and the development of the technological platform. For the Business view, Manufacturer and Packer establish the minimum quality of the olives and the kind of analyses to be performed by the Laboratory.

For the Process view, they decide that the Manufacturer while notify the Packer when a sample is sent to the Laboratory because this means that in about two weeks' time the Packer will receive the lot that the sample belongs to. Moreover, the Manufacturer will allow the Packer to see the results dispatched by the Laboratory directly on the technological platform. Thus, the Packer does not have to communicate with the Laboratory to ensure that the quality certificate is legal. Lastly, the human resources of the enterprises are trained in this new way of working.

On the other hand, the implementation was performed using MySQL for the persistence layer, web services for the application layer and HTML for user applications. We choose a Service Oriented Architecture because the case example showed in this paper is just a part of a bigger one, so it is necessary to use technologies that support big applications are loose coupled and scalable [26]. The MySQL database contains the tables needed to store the information that is going to be exchanged and processed in the web services. The web services allow users to execute the collaborative scenarios. In this case, there are web services to store the sample data, to confirm receipt of the sample, to store the result of the analyses, and so on. Moreover, there are HTML clients to introduce the data needed for each web 
service and to invoke them. It must be pointed out that each web service is in communication with the ontologies in order to resolve semantic and syntactic conflicts. This phase ends with the drafting of the user manuals and the documentation about the technological platform.

\subsection{PHASE V: Implantation}

The fifth phase of the IRIS-Framework is the execution and monitoring of the SC. The first task is to organize training courses to show users how to use the platform. In these courses, the developers give demonstrations with data from real cases to show users how to use the platform with the HTML clients. Ad-hoc applications can then be created to connect the participants' information systems with the platform automatically, sending the information that is needed directly from the user's database to a specific web service.

\subsection{PHASE VI: Execution and monitoring}

Finally, the last activity is to put the monitoring system into operation in order to measure the interoperability performance. This measure will save the number of transactions that are carried out each day. The goal is to detect whether the number of transactions is decreasing and, if so, to find out the reasons for the reduction. Another aim is to check whether the SC fits the current situation or if business is falling.

\section{Discussion}

The main difference of the SCIF-IRIS Framework with regard to existing frameworks is that it provides a step-by-step methodology for the entire interoperability improvement project of the supply chain. This methodology sets up the tools to be used in each phase, taking into account the real characteristics of the supply chain, and can be applied whether or not enterprise models and ontologies exist. Alternatively, the Methodology can be applied using other modeling languages and tools so that enterprises would use the modeling languages they know without having to learn a new one.

According to [41] there are four dimensions of a collaborative network to reach a comprehensive modeling framework. Table 6 shows a comparison between the SCIF Framework and the characteristics to be modeled proposed in [41]. Although it is possible to model every sub-dimension following the SCIF-IRIS Framework, resources and controls are only included as ICOMs of the IDEF0 Diagram, so the future challenge is to improve the SCIF-IRIS Framework to allow practitioners to model these aspects in detail.

Table 6 Comparison between [41] and SCIF Framework

\begin{tabular}{|c|l|l|}
\hline \multicolumn{1}{|c|}{ Dimension } & Sub-Dimension & SCIF-Framework \\
\hline \multirow{3}{*}{ Structural Dimension } & Actors/Relationships & Actors conceptual Map \\
\cline { 2 - 3 } Componential Dimension & Roles & Actors conceptual Map \\
\hline \multirow{4}{*}{ Functional Dimension } & Hardware/Software Resources & IDEF0 (Mechanisms) \\
\cline { 2 - 3 } & Human Resources & IDEF0 (Mechanisms) \\
\cline { 2 - 3 } & Information/Knowledge Resources & IDEF0 (Mechanisms) \\
\cline { 2 - 3 } & Ontology Resources & Ontology / Thesaurus \\
\hline \multirow{4}{*}{ Behavioral Dimension } & Process & IDEF0 (Process) \\
\cline { 2 - 3 } & Auxiliary Process & IDEF0 (Process) \\
\cline { 2 - 3 } & Methodology & IDEF0 Diagram \\
\hline & Prescriptive Behavior & IDEF0 (Controls) \\
\cline { 2 - 3 } & Obligatory Behavior & IDEF0 (Controls) \\
\cline { 2 - 3 } & Constraints and conditions & Templates for CS Modeling \\
\cline { 2 - 3 } & Contracts and cooperation agreements & Agreement Letters \\
\hline
\end{tabular}


At the other hand, the expected result and duration of the execution of the framework is variable. It depends on the topology of the chain and the complexity of the process that have to collaborate.

Regarding to the case example, the execution of the framework took around a year. In this case, companies using the framework application benefitted in several aspects. The main benefit was that they realize that to share information with other enterprises improves their own business processes without putting the enterprise's worth at risk. In fact, collaborative information transparency and availability increases enterprise's worth because it allows enterprises businesses to improve the synchronization of internal process with the internal processes of the other participants. This was not obvious to them at the beginning of the project. Meanwhile, collaborative process execution time has decreased because even if companies were collaborating before the establishment of the collaboration network, their main communication channels for the expedition of quality certificates and the communication between two participants were the telephone, e-mail, fax and postal mail. Today, they collaborate through the technological platform in which communications are immediate and, moreover, visible for as many participants as the collaborative network requires. Thus, the manufacturer does not have to send analysis results to the packer because the packer can look up the results on the technological platform. Enterprises of the case study have a pro-active attitude to the technological platform. Information analysis applications are being developed to extract the most information possible from the technological platform with the view that this information guides decision-making for enterprises. So, the SCIF-IRIS Framework not only improves the ICT layer of interoperability; moreover it helps to align the business processes through process models and to solve the semantic alignment at process, human resources and technological levels.

Finally, it is important to point out that the participating enterprises had held business relationships for decades, yet there was some reluctance to share information among them. Therefore, it is necessary to validate the SCIF-IRIS Framework in other types of collaborative networks to verify that it adapts to all kind of relationships and collaborations among enterprises.

\section{Conclusion}

Enterprise interoperability is a tool to improve supply chain efficiency. However, there are no frameworks that guide the interoperability improvement project of the supply chain with a holistic approach. The SCIF-IRIS Framework presented in this paper is a step forward in the field of enterprise interoperability. SCIF-IRIS takes into consideration the different advancements from the academic context in the interoperability field and offers them to the supply chains. As a result, real characteristics and needs have been taken into account. The final result of the SCIF-IRIS Framework applied to a supply chain is an interoperability improvement from all the perspectives of the enterprise (business, process, technology, semantic). It facilitates the inclusion of new partners in the chain as well as its adaptation to new market requirements. Moreover, its application serves as a reference to other supply chains to identify the potential of interoperability as well as the tasks required to improve it. This should be pointed out to practitioners because there are not enough examples about how to create an interoperable supply chain.

From an academic point of view, SCIF-IRIS establishes two challenges: first, to validate its applicability to other kinds of dynamic collaborative networks apart from the supply chain and secondly, to improve the last phase (execution and continuous improvement) so that the long term operation of the collaborative network is taken into account. some challenges: first, to validate its applicability to other kinds of dynamic collaborative networks apart from the supply chain; secondly, to improve the last phase (execution and continuous improvement) so that the long term operation of the collaborative network is taken into account (a set of reference performance indicators should be defined); and finally, to research about the problem of the access rights and security policies for both allowing the right partners (and persons/roles) to have access to the necessary information (and only to this) and preventing not affected partners to have access to information that are not their business. To address this, a new dimension may be added to the framework to ensure collaborative network sustainability [42].

\section{References}


1. Mentzer, J., DeWitt, W., Keebler, J., Soonhong, M., Nix, N., Zacharia, Z., Smith, C.: "What is Supply Chain Management?" Supply chain management. pp. 1-25, Sage Publications, Thousand Oaks, CA (2001).

2. Tan, K.C., Lyman, S.B., Wisner, J.D.: "Supply chain management: a strategic perspective." International Journal of Operations \& Production Management. 22, 614-631 (2002).

3. Giunipero, L., Handfield, R.B., Eltantawy, R.: "Supply management's evolution: key skill sets for the supply manager of the future." International Journal of Operations \& Production Management. 26, 822-844 (2006).

4. Ballou, R.: "Business logistics supply chain management.." Prentice-Hall, [S.1.] (2004).

5. Christopher, M.: "Logistics and supply chain management : creating value-added networks." FT Prentice Hall, Harlow England ;;New York (2005).

6. "List of public deliverables of the INTEROP project - I-VLab Platform," http://interopvlab.eu/ei public deliverables/interop-noe-deliverables.

7. Mouzakitis, S., Sourouni, A.-M. and Askounis, D., "Effects of enterprise interoperability on integration efforts in supply chains", International Journal of Electronic Commerce, Vol. 14 No. 2, pp. 127-55 (2009)

8. Janssen M. and Feenstra A. "Service portfolios for supply chain composition: Creating business network interoperability and agility”, International Journal of Computer Integrated Manufacturing Vol. 23 Iss. (8-9), pp. 747-757, (2010).

9. Harland, C.M., Lamming, R.C., Cousins, P.D.: "Developing the concept of supply strategy." International Journal of Operations \& Production Management. 19, 650-674 (1999).

10. Chen, D., Vallespir, B., Daclin, N.: "An Approach for Enterprise Interoperability Measurement." MoDISE-EUS. pp. 112CEUR-Workshops, Montpellier, France (2008).

11. Tuma, A. "Configuration and coordination of virtual production networks", International Journal of Production Economics V. 56-57 (1998), pp. 641-648.

12. Lambert, D., Garcia-Dastugue, S., Croxton, K.: "An evaluation of Process-Oriented Supply Chain Management Framework," (2005).

13. IST-2001-507849: "ATHENA - Advanced technologies for interoperability of heterogeneous enterprise Networks and their applications," http://www.ist-world.info.

14. Lyu, J., Chang, L.: "A reference model for collaborative design in mould industry." Production Planning \& Control. 21, 428436 (2010).

15. Supply Chain Council: "SCOR: Supply Chain Operations Reference Model: Version 9.0." Supply Chain Council (2008).

16. Wu, W., Yeh, S., Fang, L.: "The development of a collaborative design chain reference model for the motorcycle industry." The International Journal of Advanced Manufacturing Technology. 35, 211-225 (2006).

17. Jardim-Goncalves, R., Grilo, A., Hassan, T., Steiger-Garcao, A.: "Semiotics-based manufacturing systems integration in the advent of a single electronic market." International Journal Of Computer Integrated Manufacturing. 23, 832-851 (2010).

18. Isaac, A., Wang, S., van der Meil, L., Schlobach, S., Zinn, C., Matthezing, H.: "Evaluating Thesaurus Alignments for Semantic Interoperability in the Library Domain." IEEE Inteligent Systems. 24, 76-86 (2009).

19. Standfor Center for Biodemical Informatics Research: "Protégé," http://protege.stanford.edu/.

20. Agostinho, C., Sarraipa, J., D'Antonio, F., Jardim-Goncalves, R.: "Enhancing STEP-based interoperabity using model morphisms.” In: Goncalves, R.J., Muller, J.P., Mertins, K., and Zelm, M. (eds.) Enterprise Interoperability II: New Challenges and Approaches. pp. 817-828Springer London, Portugal (2007).

21. Bourey, J., Grangel, R., Doumeingts, G., Berre, G.: "Deliverable DTG 2.2: Report on Model Interoperability." INTEROP Noe IST-2003-508011 (2006).

22. Dalpiaz, F., Ali, R., Asnar, Y., Bryl, V., Giorgini, P.: "Applying Tropos to Socio-Technical System Design and Runtime Configuration." Evolution of Agent Development: Methodologies, Tools, Platforms and Languages (WOA08). , Palermo, Italy (2008).

23. Knowledge Based Systems, Inc.: "Integrated DEFinition Methods," http://www.idef.com.

24. Object Management Group: "Unified Modeling Language," www.uml.org.

25. Goguen, J.A., Linde, C.: "Techniques for requirements elicitation." Requirements Engineering, 1993., Proceedings of IEEE International Symposium on. pp. $152-164$ (1993).

26. "taom4e - Project Hosting on Google Code," http://code.google.com/p/taom4e/.

27. "Eclipse - The Eclipse Foundation open source community website.," http://www.eclipse.org/.

28. "For Java Developers," http://www.oracle.com/technetwork/java/index.html.

29. Jardim-Goncalves, R., Grilo, A., Steiger-Garcao, A.: "Challenging the interoperability industry with MDA between computers in and SOA." Computers in Industry. 57, 679-689 (2006).

30. Campos, C., Chalmeta, R., Grangel, R., Poler, R.: "Maturity Model for measuring interoperability potentiality." Under Revision in The Journal of Systems and Software.

31. Čaplinskas, A.: "Requirements Elicitation in the Context of Enterprise Engineering: A Vision Driven Approach." Informatica. 20, 343-368 (2009).

32. Fuentes-Fernández, R., Gómez-Sanz, J.J., Pavón, J.: "Requirements elicitation and analysis of multiagent systems using activity theory." IEEE Transactions On Systems Man and Cybernetics Part A - Systems And Humans. 39, 282-298 (2009).

33. Gupta, A.: "A stakeholder analysis approach for interorganizational systems." Industrial management \& Data Systems. 95, 3-7 (1995).

34. "Report Manager Official page," http://reportman.sourceforge.net/index.html.

35. Chalmeta, R., Grangel, R.: "ARDIN extension for virtual enterprise integration." Journal of Systems and Software. 67, 141152 (2003).

36. Castro, J., Kolp, M., Mylopoulos, J.: "A Requirements-Driven Development Methodology." Proceedings of the 13th International Conference on Advanced Information Systems Engineering. pp. 108-123Springer-Verlag, London, UK (2001).

37. Vergidis, K., Turner, C.J., Tiwari, A.: "Business process perspectives: Theoretical developments vs. real-world practice." International Journal Of Production Economics. 114, 91-104 (2008).

38. Kim, J., Park, S., Sugumaran, V.: "A multi-view approach for requirements analysis using goal and scenario." Industrial management \& Data Systems. 104, 702-711 (2004).

39. “metodologia_elicitacion.pdf," http://www.dsi.uclm.es/asignaturas/42541/pdf/metodologia_elicitacion.pdf.

40. "GLN Allocation Rules | GS1 - The global language of business," http://www.gs1.org/1/glnrules/.

41. Camarinha-Matos, L.M., Afsarmanesh, H.: "A comprehensive modeling framework for collaborative networked organizations.” Journal of Intelligent Manufacturing. 18, 529-542 (2007). 
42. Agostinho, C., Jardim-Gonçalves, R.: "Dynamic Business Networks: A Headache for Sustainable Systems Interoperability." On the Move To Meaningful Internet Systems: OTM 2009 Workshops. pp. 194-204, Portugal (2009).

\section{Acknowledgement}

This work was partially funded by AVANZA Plan (eSISA Project, TSI-020312-2009-48) and Bancaja (P1·1B2009-11). 